\title{
FUNCIONÁRIOS PÚBLICOS, ESTADO E SAÚDE NO BRASIL *
}

\author{
Regina Maria Giffoni Marsiglia **
}

RESUMO: A centralização político-administrativa é bastante grande no Estado brasileiro, herança das condições históricas e das pollticas implementadas recentemente no país. Acompanhando o processo de transição para democracia nos anos 80 , os debates apontaram a centralizaçăo como o maior obstáculo ao desenvolvimento económico e à implantaçăo de políticas públicas baseadas no direito de cidadania. No setor saúde, o processo de centralização a partir da década de $\mathbf{2 0}$ também foi notório, tanto na saúde pública quanto na assistencia médica previdenciária. As dificuldades para a descentralização são inúmeras no âmbito geral do Estado e também no setor saúde, incluindo af as reações do próprio funcionalismo com respeito às propostas e projetos de descentralizaçăo e unificação das administrações públicas. Em função disso desejamos conhecer, em um primeiro momento, a composição desta categoria social, seu desenvolvimento na sociedade brasileira e as relações que vem estabelecendo no interior do aparelho de Estado. Assim, este artigo se propõe a apresentar algumas tendências do crescimento do funcionalismo público no pás e do segmento inserido na área de saúde na década de 80. Trabalhamos com dados do Ministério da Saúde integrantes do Sistema de Informações organizado por Roberto Passos Nogueira para os diversos Estados, entre os quais destacamos o Rio de Janeiro, Paraíba, Rio Grande do Sul e São Paulo.

* Servidor, funcionário, trabalhador: interesses e culturas organizacionais no setor público de saúde - Tese de Doutorado apresentada à F.F.L.C.H. da USP, São Paulo, 1993.

* Doutora em Ciências Políticas e Professora da Faculdade de Ciencias Médicas da Santa Casa de Misericórdia de São Paulo e da Faculdade de Serviço Social da Pontif́́cia Universidade Católica de São Paulo. 


\section{INTRODUÇÃO}

O Estado brasileiro apresenta um alto grau de centralização políticoadministrativa: as condições históricas, políticas, sociais e econômicas favoreceram essa centralização para sustentar empreendimentos econômicos e resguardar a soberania nacional (15) Esta tendência foi reforçada na história política e econômica do país: as mudanças implementadas à partir da década de 30, basearam-se em reformas administrativas visando o fortalecimento do governo central.

Por outro lado, a experiência dos governos populistas da década de 50 e parte dos anos 60 , que poderiam apontar, ainda que debilmente, para a descentralização, foram substituídas na década de 70 pelos governos militares, que fortaleceram ainda mais as estruturas centrais, "criando uma autonomia sem precedentes, na história da burocracia do continente" (15) no nível federal da administração pública.

Quando o país começou o processo de transição para a democracia no inicio dos anos 80 , o debate a respeito dos direitos de cidadania, a pressão por políticas públicas mais redistributivas e o endividamento regional, apontaram para a necessidade da descentralização do Estado, passando-se a considerar o "Estado centralizado", como o maior obstáculo ao desenvolvimento ou uma das características do subdesenvolvimento do país (2)

Analisando os princípios descentralizadores consignados na Constituição de 1988, SADEK (13) considera que as propostas de 1988 são muito diferentes das perspectivas descentralizadoras do início republicano e do 
período redemocratizante após o Estado Novo, dadas as modificações estruturais porque passou a sociedade brasileira.

Uma inovação introduzida na atual Constituição foi que, além da descentralização jurídico-política, o município passou a ter competência para tributar, foram ampliadas suas competências legislativas e foram melhor definidas suas atribuições no campo da política social, devendo possibilitar a participação popular na gestão da coisa pública.(13)

\section{O SETOR SAÚDE}

No caso particular da área de saúde, o Brasil seguiu a tradição de centralização e verticalidade nos serviços de saúde pública desde meados da década de 20, o mesmo acontecendo com os serviços de assistência médica da Previdência Social a partir da Revolução de 30: criaram-se os Institutos centralizados a nível federal e organizados verticalmente pelas várias categorias de trabalhadores.

Ao final dos anos sessenta e durante os anos 70 , a saúde pública passou por um processo de reforma administrativa com tendências à modernização e centralização nos três níveis da administração, partindo do nível federal. A Previdência Social também foi reestruturada e centralizada em dois momentos: na unificação dos Institutos dos trabalhadores urbanos em 1967 (INPS) e do conjunto dos trabalhadores urbanos, rurais e do setor público federal, em 1978 (SINPAS).

Mas o governo da Nova República comprometeu-se em "resgatar a dívida social" contraída durante o regime anterior e agravada pela crise do final 
dos anos 70 e início dos anos 80 . Os documentos do período* trataram da grave situação social do país (desemprego, miséria e pobreza de grandes parcelas da população) e do perfil do padrão brasileiro de proteção social delineado nas políticas públicas da área social: a regressividade e distorções no financiamento e utilização dos recursos; a centralização e burocratização excessiva; a fragmentação institucional pública e dificuldades para atender as clientelas especificadas na maior parte dos programas.

O governo montou uma estratégia de intervenção social através dos Planos de Emergência para combate aos problemas da fome, desemprego e miséria absoluta e dos Planos de Reformulação do Sistema Brasileiro de Proteção Social na área da Previdência, Saúde, Habitação, Educação... Os princípios que deviam orientar essas Reformulações eram: a descentralização (na vertente da municipalização); a integração dos serviços e equipamentos públicos e privados a nível local, e a participação popular nas decisões, implantações e controle das políticas (4).

Seguindo esses princípios, na área de saúde formulou-se o Programa das Ações Integradas de Saúde (AIS) em 1984, tendo em vista: o desenvolvimento da capacidade gerencial dos serviços públicos de nível estadual e municipal; a integração dos recursos financeiros, humanos e materiais oriundos desses três níveis; a valorização dos recursos humanos integrantes da equipe de saúde; a criação de instâncias de decisão e execução com representação dos vários níveis da administração pública em saúde, dos prestadores privados de serviços, dos funcionários públicos e trabalhadores do setor e dos usuários. * *

COPAG: Prioridades Sociais (1985 / 1986); I PND da Nova República (1985)

" CLIS, CRIS, CIMS - Comissões Interinstitucionais de Saúde em nivel regional, estadual e municipal. 
Os Convênios das AIS* possibilitaram o fortalecimento de muitas administrações estaduais na saúde e principalmente de administrações municipais, que até então tinham desenvolvido uma atuação muito restrita na área: as secretarias estaduais estiveram historicamente voltadas para o combate das doenças endêmicas e epidêmicas e as secretarias municipais tentavam enfrentar, ou na maioria das vezes "transferir" para os centros urbanos maiores, os problemas de atendimento de emergência dos munícipes, que eram de sua responsabilidade.

No entanto, os problemas também foram muitos, dentre os quais destacava-se: a retração dos recursos diretos das esferas estaduais e locais para a saúde, já que havia o repasse de recursos do INAMPS; a alteração do princípio de repartição proporcional dos encargos; a forte ingerência do INAMPS nas administrações estaduais e municipais de saúde; a baixa representatividade e falta de agilidade das comissões de planejamento e gestão dos serviços ${ }^{(4)}$.

As experiências das AIS foram analisadas em 1986 na 8a. Conferência Nacional de Saúde, promovida pelo Ministério da Saúde com a participação de quatro mil delegados dos vários segmentos: das direções dos serviços públicos de saúde, dos funcionários públicos do setor, dos trabalhadores do setor produtivo e dos movimentos sociais organizados. Na ocasião, os convênios das AIS foram definidos como uma estratégia de integração das várias instituições envolvidas, e apontou-se para a necessidade de ultrapassar esta fase e caminhar para as experiências de unificação dos sistemas, universalizando o atendimento para todos os segmentos da população e descentralizando a gerência para os níveis estaduais e municipais.

* O primeiro foi assinado pelo Ministro Hélio Beltrão e os demais nas gestões seguintes, de Waldir Pires e Rafael de Almeida Magalhães, no MPAS. 
DRAIBE (4), comentando estas estratégias da Nova República de propor mudanças do padrão organizacional do sistema de proteção social no país com a participação da sociedade civil, ressalta que a única alteração fundamental se deu nas áreas da saúde e da previdência, o mesmo não ocorrendo com a habitação, saneamento e a administração propriamente ditas.

ALMEIDA (1), na mesma perspectiva, ressalta que, embora o debate sobre as alternativas de mudanças encabeçadas por técnicos situados no interior do aparelho de Estado, tenha sido uma constante na área social, o exemplo mais marcante se deu na saúde, com a proposta de unificação dos serviços do INAMPS, das administrações estaduais e municipais.

Em junho de 1987, o Presidente do INAMPS criou o Sistema Unificado e Descentralizado de Saúde - SUDS, através do qual, convênios passaram a ser assinados com os Estados tendo em vista: repassar as funções de gerência dos serviços previdenciários para as secretarias estaduais, bem como a decisão e execução de contratos do INAMPS com o setor privado na região. Recomendava-se ao mesmo tempo que as secretarias estaduais descentralizassem o atendimento básico de saúde, deixando-os a cargo das secretarias municipais.

Foi iniciado um processo de fusão das Superintendências Regionais do INAMPS com as Secretarias Estaduais de Saúde, cedendo-se moveis, equipamentos e funcionários do INAMPS para as administrações estaduais e posteriormente, para as municipais. Com isto, as direções do INAMPS em nível nacional e regional perderam o poder de distribuir os recursos de forma mais acentuadamente clientelística e foram obrigadas a alocá-los de acordo com a "programação dos estados." 
As resistências políticas à descentralização são variadas: parte importante delas localiza-se na esfera do próprio governo federal, mas elas também existem nas esferas dos governos estaduais e municipais. Na primeira, porque perdem poder e nas segundas, porque devem assumir responsabilidades pela prestação de serviços públicos mais qualificados. Por outro lado, os estímulos à descentralização originam-se dos movimentos políticos regionais e locais que exigem uma redistribuição mais justa e influência das forças políticas locais na decisão e implementação das políticas públicas.

Esta proposta para a área de saúde que teve como perspectiva uma reforma profunda do sistema de saúde, iniciada na esfera administrativa colidiu desde o começo com consideráveis interesses na defesa da manutenção da ordem vigente: das burocracias e tecnocracias inseridas no setor público que perdem o manejo dos recursos e capacidade de influências; do âmbito do funcionamento das políticas públicas que passam a se reger por critérios redistributivos e de eficiência deslocando e realocando recursos; do papel e do preenchimento da função pública por parte dos profissionais da saúde; e do novo papel que se propõe para os usuários do sistema na administração, gestão e controle das unidades locais de saúde(5).

As resistências ao SUDS partiram inicialmente das lideranças políticas do Legislativo e da Presidência da República, dificultando a realização dos Convênios e a substituição das direções do INAMPS em nível regional. Posteriormente a burocracia passou a pressionar contra a transferência das direções regionais para as Secretarias Estaduais, e os funcionários tiveram vários conflitos nas administrações estaduais e municipais quando passaram a exercer suas funções nos novos locais de trabalho (4). 
Quando o Ministro da Previdência e Assistência Social, Rafael de Almeida Magalhães foi substituído, a implantação do SUDS sofreu novas pressões. Assim, mesmo após a Constituição Federal de 1988 ter aprovado a implantação do Sistema Único, descentralizado e universalizado de saúde, a maioria das administrações regionais dificultou a implantação do SUDS.

Em 1990, a Lei Orgânica da Saúde reafirmou a necessidade de avançar no processo de unificação criando o Sistema Único de Saúde, transferindo o INAMPS para o Ministério da Saúde e reforçando a competência dos municípios na prestação de serviços de saúde. Mas nesse mesmo ano, já no mandato de Collor de Mello, a gestão do Ministério da Saúde tomou duas direções: buscou uma relação direta com os municípios, sem passar pelas instâncias estaduais, e ao mesmo tempo permitiu uma recuperação da influência do INAMPS no processo, com o retorno de antigos funcionários que estavam cedidos para o nível estadual, para a direção das coordenadorias do órgão. Por outro lado, em alguns estados as Secretarias Estaduais passaram a reter em suas mãos a rede estadual e a rede recebida do INAMPS, não as repassando aos municípios, conforme era proposto pela descentralização, em uma segunda fase(7).

\section{OS FUNCIONÁRIOS PÚBLICOS E O ESTADO BRASILEIRO}

Autores preocupados com a constituição histórica da burocracia no Brasil mostram como os cargos públicos foram sendo obtidos desde o período colonial através da estrutura de parentesco, processo pelo qual grupos privados ganharam status e autoridade para representar o Estado. Nestas condições, a burocracia foi desenvolvendo um poder próprio, tornando-se importante ator na 
dinâmica política, pois pelo emprego público cooptavam-se opositores, pagava-se favores, ocupava-se setores das camadas médias ${ }^{(9)}$.

Por outro lado, a Constituição de 1934 acolheu as reivindicações dos servidores públicos civis que datavam de 1918, no sentido de terem seu estatuto. $E$ a queda dos partidos tradicionais permitiu o enfraquecimento da velha política de clientela que os políticos adotavam em relação ao funcionalismo público (3).

Neste contexto, o Governo Federal procurou criar, com o desenvolvimento da burocracia, um fator de entrave para a pressão direta das classes dominantes, e um mecanismo que the permitisse recrutar adeptos nas novas classes sociais, possibilitando ao funcionalismo público acumular o exercício simultâneo de atividades na empresa privada e no setor público(3) .

No entanto, o Estado Novo, ao chamar a administração pública para colaborar no jogo das forças políticas informais, imprimiu a ela "falsas medidas de eficiência", um crescimento exagerado e criou um corpo de funcionários públicos mal pagos e indisciplinados. De 1920 a 40, houve um incremento significativo dos funcionários públicos, tanto do ponto de vista relativo, quanto do ponto de vista absoluto, se comparados à população em geral. Houve também diferenças regionais no período: no Distrito Federal o aumento dos funcionários públicos foi 15 vezes maior que o aumento da população, em Minas Gerais foi 4 vezes maior e em São Paulo foi 2,5 vezes maior (3).

Estabeleceu-se um novo Estatuto do Funcionário, destinado apenas aos que exercessem cargos por lei com os seguintes direitos: concurso ou provas de título na admissão, estabilidade após dois anos quando concursados, e estabilidade após dez anos de trabalho para os demais. 
Mendonça refere-se ao período de 1938-45 como o período da mais ampla influência do Departamento Administrativo do Serviço Público (DASP) na administração pública no Brasil, baseado na crença da "administração científica" e abordando a questão dos funcionários com orientação mecanicista, plano de classificação de cargos, estatutos dos funcionários públicos civis da União, sistema de mérito, concursos para ingresso na função pública, rotinas regulamentadoras, cursos de aperfeiçoamento dos servidores e principalmente, a qualificação das chefias dentro do pensamento administrativo vigente, diagnóstico e centralizador (10).

Os funcionários passaram a ser divididos em dois grandes grupos: os admitidos por concursos, participando dos sistemas de promoção baseados no mérito, e os "extranumerarios", indicados por favoritismos políticos ou pessoais, fora do sistema de méritos. As autarquias ampliaram seu quadro de pessoal, crescendo o número de extranumerários e o "funcionalismo oficial", por força dos baixos vencimentos, passou cada vez mais a acumular cargos no serviço público e no setor privado, durante a Segunda Guerra. Analisando as informações sobre a burocracia civil de 1940 a 50, observa-se que, embora os dados parecessem apontar para menor crescimento do contingente, isso não exprimia a realidade e se devia ao fato dos funcionários da Previdência Social e dos serviços médico-sanitários estarem incluídos na categoria da "administração pública" no Censo de 1940 e classificados em outra categoria, de "atividades sociais", no Censo de 1950.

Segundo CUNHA (3), os dados do censo de 40 e 50 demonstravam que:

a) houve um crescimento de $10,9 \%$ do contingente de funcionários de 1938 a 43; e de $59,3 \%$ no período de 1943 a 58 ; 
b) o crescimento foi mais intenso no Distrito Federal;

c) esse crescimento do funcionalismo federal se deu para responder às crescentes exigências de atuação social, cultural e econômica do país, tendo igual processo ocorrido nos estados mais desenvolvidos do País, nos quais o crescimento das burocracias civis estaduais e municipais acompanharam a mesma tendência da burocracia civil federal(3).

As particularidades regionais do contingente de funcionários públicos civis, e a relação entre este contingente e os demais segmentos de trabalhadores inseridos no mercado de trabalho foi ressaltada por Vieira da Cunha, apontandose que entre 1940-50:

a) o crescimento da burocracia civil em relação ao crescimento da população foi maior na região Nordeste do que na região Sul;

b) proporcionalmente, a burocracia civil cresceu mais no Nordeste do que no Sul, porque no Nordeste o processo de urbanização se deu com fraca industrialização, respondendo a burocracia pública às pressões por empregos das camadas vindas da área rural;

c) proporcionalmente, a burocracia civil no Sul cresceu menos porque com o processo de urbanização, acoplado à industrialização, a migração rural encontrou outras formas de inserir-se no setor secundário, engrossando menos o terciário e, portanto, menos o setor de serviços públicos;

d) no Nordeste, a expansão da burocracia e do setor terciário em geral, divorciado das reais exigências do desenvolvimento econômico, assumiu feiçōes mais parasitárias ou de desperdício em relação às atividades 
econômicas, apresentando-se como características, o apego ao "empreguismo público" e à disciplina "frouxa" de trabalho dos servidores públicos;

e) no Sul, como a burocracia cresceu ao lado do desenvolvimento industrial, e no interior de um setor de atividades terciárias mais especializado e disciplinado, a própria burocracia pública mostrou-se preocupada em ter maior identidade e semelhança com as práticas administrativas do setor privado;

f) embora o Nordeste e o Sul polarizem dois modelos bem diferentes, na região Leste, em que a industrialização começou a acompanhar a urbanização, o crescimento da burocracia não foi tão forte, e o "empreguismo público" não tão intenso, na medida em que se multiplicaram outras oportunidades de emprego;

g) nas regiões Norte e Centro-Oeste, muito dependentes da expansão econômica das regiões mais progressistas, o setor terciário se expandiu nas suas múltiplas formas de ocupação econômica dos interesses públicos e privados. Nessas regiões, as instituições públicas federais se expandiram bastante, criando-se mais organismos locais controlados pela administração federal, do que organismos controlados pelas administrações estaduais e municipais, observando-se por isto nessas regiões, um extraordinário aumento relativo da burocracia federal civil (3).

Com respeito ao dimensionamento e composição do funcionalismo público no Brasil, já na década de 80, LACERDA \& CACCIAMALI(8) apontaram para um crescimento contínuo do nível de emprego público, da ordem de $5,58 \%$ ao ano, entre 1979 e 1988. Dos empregos gerados entre 1980-88, 59,2\% foram localizados na administração pública. 
Repetindo a mesma tendência apontada por Vieira Cunha a respeito do crescimento do funcionalismo público entre 1940-50, o incremento do emprego público durante a Nova República foi mais intenso nas regiões de menor desenvolvimento económico e industrial: Norte $(9,49 \%$ ao ano), Nordeste $(7,56 \%$ ao ano) e Centro-Oeste $(6,93 \%$ ao ano), Sudeste $(4,10 \%$ ao ano) e Sul $(3,86 \%$ ao ano) (8).

Outra característica importante, que reflete o crescimento do funcionalismo público nesse período de abertura política, principalmente entre 1982-85, foi a expansão maior do emprego público nas esferas estadual e municipal do governo: o ritmo médio de crescimento do emprego nas administrações municipais foi quase seis vezes superior ao da administração federal e mais de duas vezes e meia superior ao das administrações estaduais. Somando-se as administrações estaduais e as municipais nesse período, elas foram responsáveis por $94 \%$ dos 649 mil novos empregos gerados na administração pública no Brasil (8).

Em 1991 havia 6,8 milhões de funcionários públicos no Brasil, correspondendo a $10,9 \%$ da PEA: $23,83 \%$ na esfera federal, $50,45 \%$ nas esferas estaduais e $25,72 \%$ nas esferas municipais ${ }^{(8)}$.

A ampliação do número de empregos nas administrações públicas foi uma das maneiras de enfrentar a crise econômica e a recessão dos primeiros anos da década: tanto para criar alternativas de emprego público quando havia uma retração do setor privado, quanto para responder às pressões sociais por serviços públicos e ao clientelismo político que acompanha os períodos de abertura política. 
Na perspectiva de "resgatar a dívida social", a Nova República ampliou o emprego público, principalmente nas administrações estaduais e municipais, mais suscetíveis as pressões populares e também ao clientelismo. Ao mesmo tempo que lançou os Planos de Emergência e os Planos da Reformulação das Políticas Públicas, descentralizando a sua implementação, o que implicava menores gastos diretos para o governo federal, embora fosse necessário repassar parte dos recursos para as administrações estaduais e municipais

\section{OS FUNCIONÁRIOS PÚBLICOS NA SAÚDE}

No setor saúde, a modernização das estruturas, a especialização dos funcionários, a privatização dos serviços e a definição da política no interior do Executivo, foram bem evidentes no Pós-64. Enquanto a Previdência Social ampliou seus serviços e se tornou hegemônica nesse período na prestação de assistência médica, basicamente através do setor privado, no Ministério da Saúde e em algumas Secretarias Estaduais e Municipais de Saúde nos centros mais urbanizados como São Paulo, ocorreram reformas estruturais visando a modernização e a centralização ao final dos anos 60 e início dos 70 .

Já na transição democrática e mais acentuadamente na Nova República, houve necessidade de mudanças na composição e na atuação do funcionalismo público, diante da nova correlação de forças na sociedade e das novas relações entre Estado e Sociedade Civil, refletindo-se nos movimentos pela reformulação da política de saúde (PREVSAÚDE-1980, CONASP-1982, AIS1984, SUDS-1987 e SUS-1990).

A ampliação do número de pessoas que trabalham na área de Saúde iniciou-se ainda durante o Regime Militar: de 1970-80 foi muito superior à 
expansão em outras áreas do mercado de trabalho. Conforme trabalho apresentado por NOGUEIRA (11), enquanto a população economicamente ativa teve um incremento de $51,74 \%$, as pessoas ocupadas no setor terciário aumentaram em $79,09 \%$ e as ocupadas no setor saúde em $109,11 \%$ nessa década .

Esta ampliação pode ser explicada pela expansão dos serviços de saúde, principalmente na área pública, destinados a segmentos cada vez mais extensos da população, de acordo com o modelo de política social que foi se delineando para o setor desde meados da década de 70.

Da mesma forma, na primeira metade da década de 80 , enquanto a PEA se expandiu a 3,8\% ao ano, o emprego na área de saúde cresceu a $6,5 \%$ ao ano. E as estimativas apontam para 2,5 milhões de trabalhadores ocupados em atividades de saúde no inicio da década de 90 , mais do dobro de 1980 , quando eram 1,2 milhões (6).

Durante a década de 80 e principalmente na primeira metade, pudemos observar algumas alterações importantes, entre as quais apontamos $(11)$ :

a) crescimento do emprego no setor público de saúde no inicio da década, principalmente para profissionais com formação específica (burocracia técnica), fenômeno atribuído à existência dos convênios para as Ações Integradas de Saúde (AIS);

b) uma discreta descentralização da distribuição de empregos para médicos e enfermeiros: do nível federal para o estadual, mas muito pouco para o nível municipal. Em 1982, o nível federal abarcava ainda $41,5 \%$ dos empregos do setor de saúde. 
Dados do Ministério da Saúde para a década de 80, organizados por Roberto Passos NOGUEIRA (11), demonstram que houve no Brasil um crescimento total do número de empregos na saúde; de $37,5 \%$ entre 1981-87, e que em 1987, 55,1\% do total de empregos em saúde estavam na área pública, apontando para um crescimento do funcionalismo público, como decorrência da política de saúde que vinha sendo implementada a partir da Nova República (Tabela 1).

Tabela 1 - Número de empregados segundo categoria econômica dos estabelecimentos de saúde. Brasil, 1981, 1983, 1985 e 1987

\begin{tabular}{|c|c|c|c|c|c|c|c|c|}
\hline \multirow{2}{*}{ CATEGORIA } & \multicolumn{8}{|c|}{ ANO } \\
\hline & \multicolumn{2}{|l|}{1981} & 1983 & \multicolumn{2}{|r|}{1985} & \multicolumn{2}{|c|}{1987} & \multirow[b]{2}{*}{$\%$} \\
\hline ECONOMMICA & $n^{0}$ & $\%$ & $n^{0}$ & $\%$ & $n^{0}$ & $\%$ & $n^{0}$ & \\
\hline \multicolumn{9}{|l|}{ PÚBLICO } \\
\hline Federal & 109.131 & 21,2 & 125.264 & 21,6 & 123.821 & 19,6 & 128.974 & 18,2 \\
\hline Estadual & 103.115 & 20,0 & 131.925 & 22,7 & 145.850 & 23,0 & 175.454 & 24,8 \\
\hline Municipal & 38.858 & 7,5 & 49.672 & 8,6 & 61.230 & 9,7 & 86.117 & 12,1 \\
\hline Sub total & 251.104 & 48,7 & 306.861 & 52,9 & 330.901 & 52,3 & 390.545 & 55,1 \\
\hline \multicolumn{9}{|l|}{ PRIVADO } \\
\hline Não lucrativo & 131.423 & 25,5 & 135.644 & 23,4 & 161.547 & 25,6 & 170.569 & 24,0 \\
\hline Lucrativo & 133.209 & 25,8 & 137.615 & 23,7 & 139.029 & 22,1 & 147.830 & 20,9 \\
\hline Sub total & 264.632 & 51,3 & 273.259 & 47,1 & 300.576 & 47,7 & 318.399 & 44,9 \\
\hline TOTAL & 515.736 & 100,0 & 580.120 & 100,0 & 631.477 & 100,0 & 708.944 & 100,0 \\
\hline
\end{tabular}

Fonte: Ministério da Saúde 
As diferenças regionais são bastante grandes, seja quanto ao incremento do emprego nas administrações públicas, seja quanto ao incremento de empregos nos segmentos privados e não lucrativos do setor saúde. De forma geral, confirmam-se na saúde, as tendências gerais do emprego público no país, havendo maior incremento nas regiões menos desenvolvidas.

Já no interior do setor público, ao longo desses anos os dados confirmam a tendência de "descentralização" do emprego, isto é, aumentou proporcionalmente mais o número de empregos nas administrações estaduais e municipais do que na administração federal(12).

Para exemplificar as diferenças regionais, nos apoiamos em SCHWARTZMAN (14) que identifica quatro tipos de regiões no Brasil:

1. as regiões que no passado mais distante ou recente se constituíram como sede do governo, como foi o caso de Salvador e Rio de Janeiro. Hoje sua atividade econômica está concentrada no comércio e no setor público, constituindo-se como capitais burocráticas e urbanas;

2. as regiões "tradicionais" que experimentaram um período de progresso no passado, sofrendo depois um declínio político e econômico, como o caso das áreas de cana-de-açúcar no Nordeste e áreas de mineração de Minas Gerais. O "coronel" desempenhou aí um papel de intermediação entre os governos municipal, estadual e nacional, e ainda hoje, os elementos "tradicionais" se mantiveram, mesmo com a decadência econômica e a predominância de governos de caráter mais burocráticos em nível estadual e nacional; 
3. a região do Rio Grande do Sul que historicamente tem desempenhado um papel político no Sistema Nacional, superior a seu tamanho e importância económica. O papel político do Rio Grande do Sul em nível nacional advém mais de sua tradição militar, caudilhista, revolucionária e oligárquica, do que dos aspectos modernos e europeizados de sua economia e sociedade;

4. a região de São Paulo, que desde o início da colonização se desenvolveu independentemente da administração central $\Theta$ até 0 início da expansão cafeeira no século $X I X$ não integrou a vanguarda dos eventos nacionais. Politicamente, São Paulo não desenvolveu um papel em nível central na mesma proporção de sua importância econômica e demográfica, mesmo durante a Primeira República, no contexto da "política do café com leite".

Baseados nessa tipologia, selecionamos dentre as informações apresentadas por NOGUEIRA (12), aquelas referentes aos Estados do Rio de Janeiro, Paraíba, Rio Grande do Sul e São Paulo.

Os dados sobre o Rio de Janeiro, antiga capital da República (Tabela 2), indicam que de 1981 a 1987 :

a) a presença do setor público desde o início da década era muito forte, responsável por pouco mais de $60,0 \%$ dos empregos em saúde, continuando a crescer ao longo dos anos e chegando em 1987 com 65,1\% dos empregos;

b) no interior do setor público há um nítido predomínio do emprego na administração federal, com o dobro da administração estadual, em 1981, aumentando a concentração no nível federal em 1987, ficando com 35,8\%, enquanto os empregos no nível estadual e municipal cresceram em menor proporção que o federal; 
c) no setor privado houve crescimento ao longo da década, e os serviços privados de caráter lucrativo continuaram a oferecer maior número de empregos, do que os privados não-lucrativos.

Tabela 2 - Número de empregados segundo categoria econômica dos estabelecimentos de saúde. Rio de Janeiro, 1981, 1983, 1985 e 1987

\begin{tabular}{|c|c|c|c|c|c|c|c|c|}
\hline \multirow{3}{*}{$\begin{array}{l}\text { CATEGORIA } \\
\text { ECONOMICA }\end{array}$} & \multicolumn{8}{|c|}{ ANO } \\
\hline & \multicolumn{2}{|c|}{1981} & \multicolumn{2}{|c|}{1983} & \multicolumn{2}{|c|}{1985} & \multicolumn{2}{|c|}{1987} \\
\hline & $n^{0}$ & $\%$ & $n^{0}$ & $\%$ & $n^{0}$ & $\%$ & $n^{0}$ & $\%$ \\
\hline \multicolumn{9}{|l|}{ PÚBLICO } \\
\hline Federal & 30.695 & 33,8 & 37.187 & 37,6 & 39.251 & 37,8 & 43.087 & 35,8 \\
\hline Estadual & 15.187 & 16,8 & 15.730 & 15,9 & 17.266 & 16,6 & 18.956 & 15,8 \\
\hline Municipal & 9.119 & 10,0 & 10.404 & 10,5 & 9.586 & 9,3 & 16.261 & 13,5 \\
\hline Sub total & 55.001 & 60,6 & 63.321 & 64,0 & 66.103 & 63,7 & 78.304 & 65,1 \\
\hline \multicolumn{9}{|l|}{ PRIVADO } \\
\hline Não lucrativo & 14.855 & 16,4 & 15.560 & 15,7 & 16.681 & 16,0 & 18.021 & 15,0 \\
\hline Lucrativo & 20.932 & 23,0 & 20.033 & 20,3 & 21.071 & 20,3 & 23.902 & 19,9 \\
\hline Sub total & 35.787 & 39,4 & 35.593 & 36,0 & 37.752 & 36,3 & 41.923 & 34,9 \\
\hline$\overline{\text { TOTAL }}$ & 90.788 & 100,0 & 98.914 & 100,0 & 103.855 & 100,0 & 120.227 & 100.0 \\
\hline
\end{tabular}

Fonte: Ministério da Saúde

Os dados para o Estado da Paraíba (Tabela 3), pertencente a região tradicional do Nordeste, demonstram que:

a) no setor público estavam $65,3 \%$ dos empregos em saúde em 1981 e $66,5 \%$ dos empregos em saúde em 1987, tendo portanto crescido o número de empregos no setor público, num Estado em que ele já era bem elevado; 
b) havia um predomínio do emprego público na administração federal em relação à estadual, situação que se inverteu a partir da segunda metade da década de 80; o número de empregos na administração municipal também cresceu ininterruptamente ao longo da década;

c) no setor privado sempre houve um ligeiro predomínio do número de empregos nos serviços de caráter lucrativo em relação aos não-lucrativos.

Tabela 3 - Número de empregados segundo categoria econômica dos estabelecimentos de saúde. Paraíba, 1981, 1983, 1985 e 1987

\begin{tabular}{|c|c|c|c|c|c|c|c|c|}
\hline \multirow{3}{*}{$\begin{array}{l}\text { CATEGORIA } \\
\text { ECONOOMICA }\end{array}$} & \multicolumn{8}{|c|}{ ANO } \\
\hline & \multicolumn{2}{|c|}{1981} & \multicolumn{2}{|c|}{1983} & \multicolumn{2}{|c|}{1985} & \multicolumn{2}{|c|}{1987} \\
\hline & $n^{0}$ & $\%$ & $n^{0}$ & $\%$ & $n^{0}$ & $\%$ & $n^{0}$ & $\%$ \\
\hline \multicolumn{9}{|l|}{ PÚBLICO } \\
\hline Federal & 3.116 & 31,4 & 3.862 & 33,0 & 3.064 & 24,7 & 3.032 & 21,2 \\
\hline Estadual & 2.157 & 21,7 & 2.973 & 25,4 & 3.242 & 26,2 & 4.265 & 29,8 \\
\hline Municipal & 1.206 & 12,2 & 1.449 & 12,4 & 1.952 & 15,8 & 2.229 & 15,5 \\
\hline Sub total & 6.479 & 65,3 & 8.284 & 70,8 & 8.258 & 66,7 & 9.526 & 66,5 \\
\hline \multicolumn{9}{|l|}{ PRIVADO } \\
\hline Não lucrativo & 1.477 & 14,9 & 1.608 & 13,7 & 2.009 & 16,2 & 2.240 & 15,6 \\
\hline Lucrativo & 1.959 & 19,8 & 1.807 & 15,5 & 2.109 & 17,1 & 2.563 & 17,9 \\
\hline Sub total & 3.436 & 34,7 & 3.415 & 29,2 & 4.118 & 33,3 & 4.803 & 33,5 \\
\hline TOTAL & 9.115 & 100.0 & 11.699 & 100.0 & 12.376 & 100.0 & 14.329 & 100.0 \\
\hline
\end{tabular}

Fonte: Ministério da Saúde

Já os dados para o Rio Grande do Sul (Tabela 4) apresentam tendências bem diferentes: 
a) franco predomínio do número de empregos no setor privado em 1981 $(65,7 \%)$, que diminui um pouco em $1987(57,5 \%)$, quando comparado ao setor público;

b) no setor público houve um predomínio do emprego no nível federal em relação ao estadual, diferença que aumentou com o crescimento de ambos durante á década; o nível municipal também apresentou um incremento, mas muito pouco significativo no período (com decréscimo inclusive em 1983), e maior crescimento em 1987;

c) no setor privado predominou amplamente o número de empregos nos serviços não-lucrativos, tendência que se manteve ao longo da década.

Tabela 4 - Número de empregados segundo categoria econômica dos estabelecimentos de saúde. Rio Grande do Sul, 1981, 1983, 1985 e 1987

\begin{tabular}{|c|c|c|c|c|c|c|c|c|}
\hline \multirow{3}{*}{$\begin{array}{l}\text { CATEGORIA } \\
\text { ECONOMICA }\end{array}$} & \multicolumn{8}{|c|}{ ANO } \\
\hline & \multicolumn{2}{|r|}{1981} & \multicolumn{2}{|c|}{1983} & \multicolumn{2}{|c|}{1985} & \multicolumn{2}{|c|}{1987} \\
\hline & $n^{0}$ & $\%$ & $n^{0}$ & $\%$ & $n^{0}$ & $\%$ & $n^{0}$ & $\%$ \\
\hline \multicolumn{9}{|l|}{ PÚBLICO } \\
\hline Federal & 7.427 & 18,4 & 7.623 & 18,4 & 10.422 & 25,4 & 10.313 & 22,7 \\
\hline Estadual & 4.384 & 10,8 & 6.051 & 14,6 & 5.489 & 13,4 & 6.057 & 13,3 \\
\hline Municipal & 2.043 & 5,1 & 1.869 & 4,5 & 2.086 & 5,1 & 2.942 & 6,5 \\
\hline Sub total & 13.854 & 34,3 & 15.543 & 37,5 & 17.997 & 43,9 & 19.312 & 42,5 \\
\hline \multicolumn{9}{|l|}{ PRIVADO } \\
\hline Não lucrativo & 18.141 & 45,0 & 16.550 & 40,0 & 17.195 & 42,0 & 19.112 & 42,1 \\
\hline Lucrativo & 8.346 & 20,7 & 9.311 & 22,5 & 5.783 & 14,1 & 6.968 & 15,4 \\
\hline Sub total & 26.487 & 65,7 & 25.861 & 62,5 & 22.978 & 56,1 & 26.080 & 57,5 \\
\hline TOTAL & 40.341 & 100.0 & 41.404 & 100.0 & 40.975 & 100.0 & 45.392 & 100.0 \\
\hline
\end{tabular}

Fonte: Ministério da Saúde 
E por fim, apresentamos na Tabela 5 a situação particular de São Paulo nesse mesmo período:

a) detém o maior número de empregos em saúde de todo o país tanto na área pública quanto na área privada, concentrando $26,7 \%$ do total de empregos do setor no Brasil em 1981, e $25 \%$ em 1987;

b) apresenta um predomínio de empregos na área privada $(65,8 \%)$ em 1981 , e menor predomínio, mais ainda significativo em 1987 (58,6\% dos empregos da área privada);

c) no interior da área pública, há um nítido predomínio do emprego na administração estadual em relação à federal, sendo praticamente o dobro o número de empregos do nível estadual em relação aos do federal em 1981, e aumentando para quase quatro vezes em 1987; houve um crescimento importante também do número de empregos nas administrações municipais ao longo do período, chegando a mais que dobrar entre 1981-87;

d) na área privada, o número de empregos nos serviços não-lucrativos e lucrativos manteve-se mais ou menos equilibrado até 1983, sendo que a partir daí, os serviços privados lucrativos parecem ter estagnado, enquanto 0 número de empregos nos não-lucrativos teve um incremento importante;

e) cada um dos tipos de serviços oferece um grande número de empregos em São Paulo se comparados ao Brasil como um todo, demonstrando-se como todas as modalidades são bem fortes e desenvolvidas no Estado, exceto os da administração federal que são proporcionalmente menores. 
Tabela 5 - Número de empregados segundo categoria econômica dos estabelecimentos de saúde. São Paulo, 1981, 1983, 1985 e 1987

\begin{tabular}{|c|c|c|c|c|c|c|c|c|}
\hline \multirow{3}{*}{$\begin{array}{l}\text { CATEGORIA } \\
\text { ECONOOMICA }\end{array}$} & \multicolumn{8}{|c|}{ ANO } \\
\hline & \multicolumn{2}{|c|}{1981} & \multicolumn{2}{|c|}{1983} & \multicolumn{2}{|c|}{1985} & \multicolumn{2}{|c|}{1987} \\
\hline & $n^{0}$ & $\%$ & $n^{0}$ & $\%$ & $n^{0}$ & $\%$ & $n^{0}$ & $\%$ \\
\hline \multicolumn{9}{|l|}{ PÚBLICO } \\
\hline Federal & 11.980 & 8,7 & 12.717 & 8,3 & 10.499 & 6,7 & 10.374 & 5,7 \\
\hline Estadual & 22.627 & 16,5 & 29.352 & 19,1 & 26.358 & 16,9 & 39.403 & 21,8 \\
\hline Municipal & 12.441 & 9,0 & 16.092 & 10,5 & 20.816 & 13,3 & 26.131 & 13,9 \\
\hline Sub total & 47.048 & 34,2 & 58.161 & 37,9 & 57.673 & 36,9 & 74.908 & 41,4 \\
\hline \multicolumn{9}{|l|}{ PRIVADO } \\
\hline Não lucrativo & 46.128 & 33,6 & 48.699 & 31,7 & 52.098 & 33,4 & 59.788 & 33,1 \\
\hline Lucrativo & 44.206 & 32,2 & 46.565 & 30,4 & 46.352 & 29,7 & 46.100 & 25,5 \\
\hline Sub total & 90.334 & 65,8 & 95.264 & 62,1 & 98.450 & 63,1 & 105.888 & 58,6 \\
\hline TOTAL & 137.382 & 100,0 & 153.425 & 100,0 & 156.123 & 100,0 & 180.796 & 100,0 \\
\hline
\end{tabular}

Fonte: Ministério da Saúde

Assim podemos verificar que o Estado de São Paulo detinha em 1987, respectivamente, as seguintes percentagens do total de empregos em saúde do Brasil: $8,1 \%$ do público federal, $22,5 \%$ do público estadual, $29,2 \%$ do público municipal, $35 \%$ do privado não-lucrativo e $31,4 \%$ do privado lucrativo (Tabela 6).

Conclui-se daí que um pouco mais de 1/3 dos empregos em saúde das administrações públicas de nível municipal estão em São Paulo, bem como dos empregos da área privada lucrativa e não-lucrativa. Por outro lado mais de 
1/5 dos empregos de saúde de nível estadual estão em São Paulo (em 1987 eram quase 40 mil funcionários) e apenas é menos importante o número de empregos da administração federal em saúde em São Paulo, caindo ao longo da década de $11 \%$ para $8,1 \%$ do total do Brasil. Isto confirma as observações de Schwartzman a respeito da situação de São Paulo a nível nacional: embora sendo o Estado que mais arrecada, é o que conta com menor número de funcionários de nível federal no setor saúde.

Estas características, a proporção entre empregos no setor público e no setor privado, a composição interna do setor público por nível de administração e a composição interna do setor privado em lucrativos e nãolucrativos, interfere na implantação do Sistema Único de Saúde e, com mais razão nas peculiaridades regionais que o processo vem assumindo.

Tabela 6 - Participação percentual do Estado de São Paulo no total de empregos em saúde no Brasil, 1981 e 1987.

\begin{tabular}{lcc}
\hline \multicolumn{1}{c}{ São Paulo } & 1981 & 1987 \\
\hline Serviço Público Federal & 11,0 & 8,1 \\
Serviço Público Estadual & 22,0 & 22,5 \\
Serviço Público Municipal & 32,0 & 29,2 \\
Privado Não Lucrativo & 35,1 & 35,0 \\
Privado Lucrativo & 33,2 & 31,4 \\
\hline
\end{tabular}

Fonte: Ministério da Saúde 


\section{REFERÊNCIAS BIBLIOGRÁFICAS}

01. ALMEIDA, M.H.T. de Direitos sociais, organização de interesses e corporativismo no Brasil. Novos Estudos CEBRAP, 25:50-60, 1989

02. BANCO MUNDIAL. Relatório sobre o desenvolvimento mundial, Washington, 1988

03. CUNHA, M. W. V. da $O$ sistema administrativo brasileiro 1930-1950. Rio de Janeiro, MEC, 1963. p. $63-4$

04. DRAIBE, S. A historiografia da politica social brasileira. In: Teorias e tipologias sobre a emergência e desenvolvimentos do Welfare State. s.d., p. 53-81

05. GERSCHMAN, S. Sobre a formação de políticas sociais. In: TEIXEIRA, S.M.F. org., Reforma sanitária: em busca de uma teoria. São Paulo, Cortez Ed./ABRASCO, 1989, p. 121-22.

06. GIRARDI, S.N. La fuerza de trabajo en el setor salud: elementos técnicos y evidencias empíricas, in Revista Educación Médica y Salud, vol. 25, n 1, p. 41-4.

07. JUNOUEIRA, L.A.P. \& INOJOSA,R.M. Gestăo dos serviços públicos de saúde: em busca de uma lógica da eficácia. Rev. Adm. Pública, 26(2): 20-31, 1992.

08. LACERDA, G.M. \& CACCIAMALI, M.C. Processos de ajustamento, emprego público e diferenciações regionais do mercado de trabalho. S. Paulo em Perspectiva, 6(3):70-77, 1992.

09. LUCCHESI, G. Burocracia e politica de saúde; arena ou ator? In: TEIXEIRA, S.M.F. org. Reforma Sanitária: em busca de uma teoria, S.Paulo, Ed. Cortez Ed./ABRASCO, 1989, p. 164

10. MENDONÇA, J.R.A. Treinamento e a funçăo estratégica do desenvolvimento de recursos humanos na reforma administrativa. In: Rev. Adm. Püblica, 21, 130-41, 1987.

11. NOGUEIRA, R.P. Dinámica do mercado de trabalho em saúde no Brasil (1970-83) Washington, D.C., Organização Panamericana da Saúde, 1985, p. 20.

12. NOGUEIRA, R.P. Emprego em saúde por natureza médico-administrativa dos estabelecimentos: 1981-1987. Bol. Inform. SUS / RH, 1(1):8, 1992.

13. SADEK, M.T. Poder local: perspectivas na nova ordem constitucional. São Paulo em Perspectiva, 5(2):9-15, 1991 
14. SCHWARTZMAN, S. - Bases do autoritarismo brasileiro . Rio de Janeiro, CAMPUS, 1988.

15. TEIXEIRA, S.M.F. Descentralização dos serviços de saúde: dimensões analíticas. Rev. Adm. Pública, 24: 78-99, 1990. 